\title{
Brujas y apariciones en la Cuchilla de la Buenavista: Otras formas de recordar el conflicto
}

\author{
María Angélica Garzón / Universidad Pedagógica y Tecnológica de Colombia \\ Diana Marcela Bernal / Universidad Pedagógica y Tecnológica de Colombia
}

\section{Introducción}

La provincia de Lengupá es un territorio de $1.312 \mathrm{~km}^{2}$ de extensión ubicado en el departamento de Boyacá, Colombia, que se encuentra en el piedemonte llanero donde la Cordillera Oriental de los Andes desciende hacia la región de la Orinoquía. Destaca por su abundante vegetación, diversidad de afluentes de agua que la atraviesan y un clima de fuertes inviernos y pocos veranos. Estas condiciones posibilitan la producción agrícola y ganadera que ha tenido un auge importante en la provincia, manteniéndose hasta hoy como una de sus principales vocaciones económicas. Agrupa siete municipios: Rondón, Berbeo, Campohermoso, Páez, San Eduardo, Zetaquirá y Miraflores, este último, capital de provincia.

Como gran parte de la geografía colombiana, Lengupá cuenta con una historia de violencia que ha marcado de forma importante su territorio. Asesinatos, masacres y desplazamientos forzados son algunos de los hechos que tejen tal historia. Pocos de ellos documentados, registrados o conocidos más allá de memorias locales que circulan entre familiares y vecinos pero que poco repercuten en construcciones narrativas que, como relatos emblemáticos de mayor envergadura, permiten reconocer los efectos del conflicto armado en la población del departamento de Boyacá y, para este caso en particular, de la provincia de Lengupá. ${ }^{1}$

De acuerdo con los datos del Registro Único de Víctimas (RUV 2020), en esta provincia se pueden rastrear hechos asociados al conflicto armado desde el año 1984 hasta 2017, con un saldo de aproximadamente 5.920 víctimas de las cuales el $50 \%$ corresponde a hombres, el $48 \%$ a mujeres, el $0,05 \%$ a población LGBTI y el restante a población indeterminada, entre las edades: 0 a 5 años $(4,56 \%), 6$ a 11 años (7,52\%), 18 y 28 años (19,39\%), 29 y 60 años $(43,85 \%)$ y 61 y 100 años $(7,21 \%)$. Entre los hechos de violencia que más se producen, se encuentran en orden de intensidad: desplazamiento forzado, amenazas, homicidios, desapariciones forzadas, secuestro, actos terroristas, pérdida de muebles o inmuebles, tortura, y delitos contra la integridad sexual. Lengupá es la segunda provincia a nivel departamental que presenta mayores registros de violencia, antecedida solamente por la de Occidente.
Diversas disputas han propiciado el desenvolvimiento del conflicto armado en el departamento de Boyacá a lo largo del siglo XX. Entre las más destacadas se encuentra la violencia interpartidista, caracterizada por la búsqueda del poder de dos fuerzas políticas opuestas -liberales y conservadores- la cual se desarrolla a partir de los años treinta del siglo XX (Acuña y Guerrero 2008). También, cabe destacar la lucha armada desplegada a nivel nacional por guerrillas como las Fuerzas Armadas Revolucionarias de Colombia (FARC), el Ejército de Liberación Nacional (ELN) o el Ejército Popular de Liberación (EPL) desde la década del sesenta, como parte de una confrontación abierta con un régimen bipartidista y en respuesta a la exclusión política propuesta por el mismo (CNMH 2013). Finalmente, es importante mencionar el conflicto social, político y económico que se alimenta del narcotráfico, la presencia paramilitar y la bonanza esmeraldera en la década del ochenta: la llamada "guerra verde" o "guerra de las esmeraldas" tal y como lo sintetiza Guerrero Barón (2008):

Luego de los episodios del final de la Violencia como período histórico, la región se caracterizó por una fase denominada por los especialistas como bandolerismo endémico (...) pronto la región se convirtió en refugio de bandidos que con sus armas regulaban negocios, asaltaban muchas veces a quienes acababan de volverse ricos y cometían todo tipo de tropelías (...) desde entonces se desarrolló una paranoia colectiva y armada que imaginaba que las pequeñas guerrillas liberales o comunistas iban a tomar por asalto las minas, ante lo cual había que resistir con las armas. (122)

Todos estos conflictos estuvieron presentes en Lengupá. Primero con la presencia de los "Chusmeros," disidencias de las guerrillas de los años cincuenta que buscaron llegar desde los llanos al centro del país atravesando la provincia (Martínez 2017). Posteriormente, en la década del noventa, el Frente 38 de las FARC incursionó en los municipios de San Eduardo y Zetaquirá buscando recursos, alimentación y apoyo ideológico de la población. Después de esto, ya finalizando la década, arribó el paramilitarismo bajo el mando de Dumar Romero y su grupo denominado "Los Masetos", que tenía por misión exterminar a la guerrilla y sus colaboradores en la 
región. Durante todo este tiempo, Lengupá fue sometida a un régimen de terror del que poco se sabe, pero mucho se recuerda (Pérez y Giraldo 2018). Las narraciones de las personas de la región aluden a esta violencia de forma casi indistinta, donde los recuerdos poco diferencian entre el actuar de las guerrillas liberales y el de las guerrillas más contemporáneas o los grupos paramilitares.

De todo esto, llama nuestra atención como mujeres, investigadoras y habitantes de la región, la forma en que pobladores de los municipios de Miraflores y Páez construyen estrategias de rememoración que transitan entre la ritualidad de las conmemoraciones, la reclamación de derechos como justicia, verdad y reparación, la asignación de sentido al dolor, la pérdida y la memoria a través de seres mágicos que, a manera de testigos y guardianes de lo sucedido, habitan lugares marcados por la violencia del conflicto armado. Es el caso de la Cuchilla de la Buenavista y la aparición de brujas, espantos, ánimas y seres que al tener una muerte violenta se niegan a dejar la vida o, en este caso, dejar de testimoniar (Garzon Martinez).

Tomando distancia de paradigmas que enuncian la construcción de las memorias del conflicto como un trabajo elaborado desde saberes expertos - la historia - nos interesamos por la oralidad y la forma en que figuras como las brujas constituyen un hito a partir del cual las comunidades que habitan el camino del Mincho interpretan pasados violentos y resignifican lugares marcados por el terror. De allí que el presente artículo se proponga reflexionar sobre la relación entre lugares, prácticas de recuerdo y órdenes simbólicos representados por seres no humanos (Bernal 2019) que a manera de estrategias culturales se despliegan para preservar memorias colectivas en torno al conflicto armado.

Para esto, acudimos a los resultados del ejercicio de cartografía social realizado con pobladores de la vereda Morro Abajo (Miraflorez, Boyacá) en 2018 como parte de la investigación: "El Camino del Mincho: Rutas de valoración patrimonial", así como a las entrevistas que durante la investigación se desarrollaron con pobladores del Camino del Mincho y de los municipios de Miraflores y Páez en la provincia de Lengupá. Con el fin de organizar nuestros argumentos, iniciamos con la presentación del camino del Mincho, la Cuchilla de la Buenavista y la violencia sufrida en este territorio. Pasamos a exponer la presencia de las brujas y apariciones en la Buenavista, su actuar y significado. Finalizamos reflexionando sobre la imagen de la bruja como registro que posibilita la reconstrucción de memorias asociadas al conflicto armado colombiano.

\section{El Mincho: una historia de violencia}

Conocimos el camino del Mincho por un interés patrimonial; desde una investigación que buscaba valorarlo para postularlo como itinerario cultural. Al recorrerlo, además de disfrutar de sus riquezas naturales y de andar trayectos ya realizados por comerciantes y migrantes que propusieron toda una mixtura cultural y poblacional a partir de sus intercambios económicos en la región, nos encontramos con una serie de historias de violencias que por generaciones han marcado buena parte de la vida de la población de Lengupá. Nos acercamos al camino a través de una cartografía social realizada con pobladores de la vereda Morro Abajo, que hace parte del trayecto. En este ejercicio buscamos observar la forma en que se describe el recorrido y las memorias de tradiciones y saberes relacionados con este lugar.

Realizamos el taller con la Junta de Acción Comunal de la vereda y gracias a la invitación del señor Tito Velásquez, su presidente. $\mathrm{Al}$ encuentro asistieron varias personas, entre ellas abuelos, adultos, jóvenes y niños. Al finalizar el ejercicio hicimos una socialización para conocer las historias del camino. Se nos habló de la arriería, plantas medicinales, la lucha entre conservadores y liberales, y de cómo Dumar había hecho de la Cuchilla de la Buenavista un patíbulo. El Mohán, el Yato y la zorra perruna, entre otros personajes, reclamaron protagonismo. Aparecieron como moradores no humanos del camino (Bernal 2019) o como aquellas huellas que se niegan a desaparecer y que permanecen a manera de recordatorios de los que alguna vez lo recorrieron (Ingold 2018): hombres y mujeres que ahora, en cuerpos de personajes propios de la tradición oral, hacen parte de su trayecto como un vecino más.

En el marco del taller, las personas que participaron del mismo elaboraron dibujos del camino. En unos, detallaron su recorrido, sus posadas, sus puentes. Otros, se enfocaron a la diversidad de flora y fauna que existe en la región. La mayoría ubicó las casas de los vecinos que habitan el camino e hicieron referencia a otros moradores, aquellos seres mitológicos que integran buena parte del folclor colombiano, los cuales son protagonistas de mitos y leyendas. Es el caso del Mohán, un ser representado como un hombre alto, corpulento y de largas barbas, que fuma tabaco y vive en cavernas ubicadas cerca de ríos. Este personaje aparece en diversas regiones del país ya sea para premiar con oro a los hombres o robarse a las mujeres. En Lengupá, su temperamento enfurecido hace que los ríos se salgan de su curso.

Recorrer el camino del Mincho significa transitar por el palimpsesto de las múltiples historias que ha vivido, de sus personajes y de las huellas que lo caracterizan: la tierra por la que caminaron sus indígenas, el empedrado por el que transitaron campañas libertadoras y el asfalto del progreso. Hay trayectos que han desaparecido, otros apenas se dejan 
adivinar, unos son utilizados para el derechazo y en otros, los arrieros fueron sustituidos por automóviles, buses y camiones (Bernal 2019). ${ }^{2}$ La historia del camino se remonta a la época de los indígenas Teguas, población que habitaba parte del territorio de la provincia de Lengupá y de los llanos orientales: o que hoy se conoce como los municipios de Campohermoso, Santa María, Macanal, San Luis de Gaceno y Aguazul. Esta época corresponde también a la presencia de indígenas muiscas en Tunja, Ramiriquí, Sogamoso y Garagoa (Huertas 1995).

Los pueblos indígenas intercambiaron algodón, miel y plumas traídas de los llanos orientales por mantas y tubérculos de las tierras altas. Al parecer, los Teguas pagaban tributo al cacique Sugamuxi y Garagoa (Rodríguez 1997). Para 1857, el camino hacía parte de un comercio vigoroso de intercambio del algodón cultivado en Páez y los llanos orientales, desmontado en Miraflores y llevado a la ciudad de Tunja y a la textilera de Samacá (Pardo 2016).Tras la bonanza del algodón en 1893, se construye la salina en el municipio de Chámeza y con ello surge la necesidad de empedrar el camino para facilitar el paso de mulas. Los arrieros recorren el trayecto "subiendo," como narraron pobladores de la región, con sal y ganado desde Chámeza y "bajando" con víveres traídos de las ciudades de Tunja y Bogotá.

La constitución de la ruta de la sal (Pérez 2003) significó para el camino una activación social y económica importante. Dentro de sus aproximadamente 16 kilómetros de recorrido se construyeron ocho posadas que recibían, hospedaban, alimentaban y daban bebida a arrieros y muleros. A partir de los años de 1920 y1950 se vivió una época de abundancia para quienes transitaban el camino. Antiguos arrieros intercambiaban sal traída de Chámeza por víveres en Miraflores. Una vez el transporte de sal termina y su auge comercial entra en declive, empieza en Lengupá el cultivo y comercialización del café hacia la década 1950 , proyecto nacional que exige conectar territorios por vías terrestres para automóviles. El camino compite con la idea de modernizar la producción y la necesidad de grandes vías, y finalmente pierde, ante el imperioso asfalto.

Hacia los noventa, el Mincho cobra un protagonismo fugaz al convertirse en ruta para pasar el "tubo" u oleoducto central que conecta a los llanos orientales con el Mar Caribe en el municipio de Coveñas, departamento de Córdoba. Ya para esta época, el camino era secundario o reservado como un espacio veredal y comunitario. Su función de conectar municipios y propiciar el comercio se trasladó definitivamente a la carretera denominada del Progreso. Hoy, el camino hace parte de la vida social de la vereda, pues permite la interacción entre los vecinos; es un espacio de encuentros donde las personas se saludan y conversan mientras se trasladan de un lugar a otro.
La Cuchilla de la Buenavista hace parte de este recorrido. Con una longitud de $12.8 \mathrm{~km}$ y una altura de 2.600 metros sobre el nivel del mar, limita con las poblaciones de Miraflores, Páez y Campohermoso, y se extiende desde el río Lengupá hasta la parte más alta de la vereda Morro Arriba. Esta formación montañosa caracteriza al paisaje del camino al proponer su trayecto más exigente, que recompensa al caminante con una vista de espesas nubes blancas o de la profundidad del cañón del río Lengupá. Llegar hasta la Buenavista fue el primer reto que emprendimos como investigadoras. Arribar a la cumbre, en nuestro primer recorrido, nos significó alegría y entusiasmo porque casi podíamos tocar las nubes con nuestras manos, aunque con precaución de no acercarnos demasiado al vacío, pues el fuerte viento que empujaba nuestros cuerpos nos alertaba de la altitud alcanzada. Ese día no pudimos ver el río porque todo estaba nublado; sin embargo, nuestra guía nos dijo que la "caída era grande" y que allí desaparecían cuerpos.

Durante el ejercicio de cartografía social realizado para la investigación y en las entrevistas que lo acompañaron, los habitantes de Miraflores y de Páez hablaron constantemente de la Buenavista. Algunos recordaron los episodios de violencia ocurridos en ella, otros comentaron sobre el paso del "tubo" del oleoducto y gasoducto que la cruza y, otros tantos, de los mitos y espantos que la habitan. Pobladores del camino señalan que la Cuchilla es un lugar donde prima el silencio debido a las masacres y asesinatos allí ocurridos. Un silencio que encontramos común a los pobladores del camino, quienes guardan recelo al hablar con desconocidos, gente que no sea de la región o mujeres como nosotras, que, curiosas, interrogan sobre lo sucedido. El silencio manifiesta la profunda herida social provocada por la violencia.

A pesar de que conmemoraciones y otras acciones que reclaman verdad, justicia y reparación en Colombia comienza a ser usuales, en Lengupá todavía son tímidas. En la Buenavista, cada 10 de diciembre, fecha en la que se conmemora el día de los derechos humanos, se realiza una peregrinación que visibiliza a las víctimas de la insurrección paramilitar.

De acuerdo con las entrevistas realizadas, fueron varios los hechos de violencia que tuvieron lugar en el camino del Mincho; entre ellos, "la carrera de la muerte"-masacre en la que Chulavitas, fuerzas militares de los conservadores, obligaron a liberales que vivían en la vereda de Morro Abajo a correr por el camino descalzos y dispararon a quienes perdían el equilibrio y caían al piso-, la toma de Páez por parte de liberales en los años cincuenta, o las trincheras construidas por el Eército para sorprender a las guerrillas que transitaban por el Mincho (Pérez y Giraldo 2019). ${ }^{3}$ Con la llegada del oleoducto central, en el camino se vuelve frecuente la presencia de militares y paramilitares (Pérez y Giraldo 2019). Estos últimos toman el control territorial de los municipios de Miraflores, Páez, Berbeo, San Eduardo y Zetaquira desde los años noventa. 
Según lo conversado con pobladores de Miraflores y Páez, el régimen paramilitar tuvo por objetivo el control poblacional y la regulación de conductas mediante prohibiciones. De acuerdo con lo narrado por algunas personas de la región, los paramilitares prohibían embriagarse, prostituirse, robar, deber dinero o ser homosexual. Las desobediencias eran castigadas con la muerte, la extorsión o el reclutamiento forzado. La permanencia en el territorio de estos grupos armados finaliza en 2004 con la desmovilización pactada con el gobierno nacional, sin que ello signifique una pacificación del territorio, pues dirigentes paramilitares como "Martín Llanos" se negaron a acogerse al proceso de desmovilización, disputándose el control poblacional con otros grupos paramilitares.

\section{Las Brujas de la Buenavista}

Apariciones, espantos y seres mitológicos moran el camino del Mincho. En los relatos de las personas entrevistadas para esta investigación, encontramos que estos seres suelen estar relacionados con accidentes geográficos, especialmente altos, peñas, cuchillas y quebradas (Suárez Guava 2009, Bernal 2019). Aparecen para asustar a las personas alejándolas de riquezas escondidas, aleccionar a hombres infieles y borrachos como la zorra perruna, realizar intercambios como el Mohán, que negocia oro por tabaco, o para recompensar (Carrillo 1997). Ahora bien, estos seres no se presentan ante cualquier persona sino a "quien le conviene," de acuerdo a lo relatado en las entrevistas; es decir, las manifestaciones tienen sus destinatarios, usualmente personas que premian por su buen comportamiento o que aleccionan con sustos o maldiciones.

En la Cuchilla de la Buenavista, las brujas toman la apariencia de la guala (ave similiar a la lechuza), aparecen en las noches para sobrevolar la Cuchilla o para molestar a quien cruza por ella: "en la noche, si uno va por ahí solo, por el camino, pasan y lo tumban, a mí me han tumbado y se ven es ahí como una guala, pero no más," comenta un habitante del camino. ${ }^{4}$ Las brujas se le presentan a las personas para "molestarlas" o atemorizarlas a través de su indiferencia. De ellas solo se sabe que hay que golpearlas para que se vayan, darles "juete," como nos dijo una mujer: "eso dicen que se aparecen por el camino, y ellos dicen que ajá, que les tiran juete, juete en los brazos." ${ }^{\circ}$ No hablan, no señalan, no recompensan, no piden nada a cambio. Solamente merodean por la Cuchilla, la sobrevuelan en silencio y de un momento a otro desaparecen. Al parecer, no tienen un destinatario específico.

En ocasiones, las brujas son acompañadas por apariciones o fantasmas. Personas que, en fila con una vela encendida, se lanzan una a una al abismo. En el ejercicio de cartografía social realizado con habitantes de Morro Abajo, se dibujó la Cuchilla, las brujas y los fantasmas. Omar, conductor que nos acompaña en nuestro recorrido, ratificó la historia. Los fantasmas aparecen en la noche con una luz encendida y en fila van lanzándose al rio Lengupá. Por su parte, pobladores de Miraflores narran el mismo relato haciendo alusión a la violencia de los cincuenta cuando en la Buenavista se instalaron soldados del ejército, quienes presenciaron la procesión lanzándose al vacío. Estas presencias son significadas por las personas entrevistadas como almas en pena de los muertos que cayeron a las aguas del río Lengupá durante la violencia sufrida en la región. Como lo hemos señalado, desde aproximadamente la década del treinta del siglo XX, la provincia vive una época de violencia continua. Por el camino del Mincho han transitado guerrillas, militares, paramilitares y víctimas que, tras ser trasladadas hasta la Cuchilla, desaparecieron en las laderas o en el río. En nuestro primer recorrido por el camino, al aproximarnos a la Cuchilla preguntamos a Omar por el nombre de la misma, y él nos respondió: "La Buenavista o el tobogán de Dumar."

El paramilitarismo arribó a la provincia de Lengupá hacia la década de los ochenta cuando, enriquecidos por el negocio de las esmeraldas, algunos de sus empresarios y narcotraficantes asociados se interesan por la compra de tierra en los llanos. Figuras como Víctor Carranza, Gonzalo Rodríguez Gacha o Héctor Buitrago, este último proveniente del municipio de Páez, se hicieron con haciendas en Meta y Casanare y conformaron, además, ejércitos privados que defendían sus propiedades y a ellos mismos de la amenaza guerrillera. Hacia 1982 aparecen en el territorio "Los Masetos," grupo que adelantó acciones armadas, particularmente contra miembros de la Unión Patriótica a quienes tildaron de: "guerrilleros que integraron un partido, pero no dejaron de ser guerrilleros" (Así creció 2011). ${ }^{6}$ Dumar Romero fue lugarteniente de Víctor Carranza y comandó a Los Masetos en la provincia de Lengupá, ubicando su centro de operaciones en Miraflores. Desde allí ejecutó una política de exterminio mediante la limpieza social. Coaptó funciones del Estado e impuso su orden:

Dumar Romero estableció una oficina en el Matadero, donde despachó y sesionó no solo en lo correspondiente con la organización criminal, sino también, en lo referente a todos los problemas y quejas que presentaron sectores legitimadores de la población. (Testigo n. ${ }^{\circ} 8,2018$ ). También convocaron al sector comercial y a las familias pudientes, y les exigieron la colaboración con aportes económicos, que irónicamente tuvieron que consignar en una cuenta bancaria a nombre del jefe paramilitar (Pérez Jiménez y Giraldo 2018, 67).

En 1995, Dumar y Los Masetos son expulsados de Miraflores por el Ejército Nacional. De él y su grupo no se vuelve a tener noticia en la provincia, pero su presencia permanece en un paisaje transformado por sus acciones: "La Buenavista o el tobogán de Dumar." Los referentes espaciales hacen parte de los relatos enunciados por poblaciones que han 
vivido la violencia del conflicto armado. Para Blair (2013) la espacialidad construye memoria en tanto recurre a recuerdos geográficos y asociados al cuerpo; los dos se convierten en espacios heridos al ser inscritos por la violencia. Relata una de las mujeres entrevistadas:

Yo vivía en una vereda de un municipio cercano a éste, se llama la lejanía; yo tenía como unos nueve años cuando empezaron a llegar unos grupos armados, no sé si era la guerrilla o los paramilitares [...] sacaron a mi papá de la casa y le dijeron que tenía que irse con ellos. Yo estaba muy pequeña en ese momento, llorando les dije que por qué se llevaban a mi papá. Me respondieron con voz amenazante: ¡cállese o a usted también no la llevamos; no se la rebajo, la mato y la voto al rio!

En su relato, la mujer insiste: "en ese tiempo perseguían mucho a los niños: por eso nos escondimos. Eso se llevaban familias completas amarradas de las manos y pies, las votaban al río." Las palabras de la mujer refieren la Buenavista describiendo los sucesos que la convirtieron en lugar temido por los habitantes de Miraflores y Páez. El conflicto armado en Colombia ha legado a sus poblaciones una serie de paisajes y geografías que narran desde su transformación experiencias y efectos de la violencia. Ésta ha trastocado significados y sentidos de lugar al convertir casas en trincheras, vecindarios en pueblos fantasmas, y lugares colectivos en cementerios. Para los arrieros que transitaron el camino del Mincho comercializando con ganado, sal y otros productos, la Cuchilla de la Buenavista significó una frontera que anunciaba el pronto final de su faena; para los soldados liberales asentados en su cumbre representó el límite a defender, para Dumar y Los Masetos un patíbulo en el que se juzgó y condenó a muerte.

Hoy en día, la Buenavista es un recordatorio para la población de Miraflores y Paéz de los sucesos vividos, de las personas desaparecidas y de los muertos que se llevó el río sin la posibilidad de un entierro adecuado. La Buenavista es un lugar liminal custodiado por brujas, donde las relaciones entre la vida y la muerte no terminan de resolverse. Ellas hacen parte del paisaje que reclama ante el horror, el dolor y años de historia de violencia padecidos. Acompañan a las ánimas en su trasegar eterno, presentándose ante quienes han escuchado la historia de Chulavitas, guerrilleros, militares, paramilitares y maseteros. No son esposas, madres o hermanas. Son espíritus dolientes que moran lugares donde asesinaron, masacraron y desecharon cuerpos en los abismos, habitando "un espacio intermedio, hecho que les permite moverse, aparecer y desaparecer conjurando de alguna forma la ley que los condenó" (Eljaiek-Rodríguez 2019, p.19).

\section{Brujas: acompañantes, guardianas y narradoras}

Las brujas, nos dicen Ehrenreich e English (2006), fueron mujeres sanadoras que ayudaban a poblaciones campesinas con sus conocimientos de medicina tradicional. Su represión fue la primera parte de una lucha por expropiar este conocimiento para trasladarlo al plano de la ciencia médica, dominada por hombres que juzgaron a las mujeres como charlatanas, malévolas, brujas. ${ }^{7}$ Para el caso de América Latina y el Caribe, las brujas fueron mujeres perseguidas por el régimen colonial que practicaban religiones antiguas, saberes tradicionales de sanación o poseían vínculos con la naturaleza.

Durante la Colonia, las brujas en gran parte de América Latina y el Caribe adelantaron luchas contra la imposición de nuevas religiones y formas de ser en el mundo preservando conocimientos y prácticas milenarias. En un momento en que la defensa de las tradiciones comenzaba a estar en estrecha relación con la resistencia política, las brujas se integraron de forma importante en la vida cotidiana de las comunidades, sus relaciones y decisiones (Federici 2010). A pesar de su persecución, la imagen como mujeres sanadoras, conocedoras de los secretos de la naturaleza y habitantes de montañas, lagunas y otros lugares mágicos, persistió en el imaginario popular. Como lo señala Różańska (2011), en Latinoamérica desde la tradición indígena hasta la sociedad contemporánea permanecen arquetipos de mujer fuertemente asociados con lo sobrenatural, dotadas de poder sobre la vida y la muerte.

En el contexto colombiano, abundan relatos de brujas, sanaciones o hechizos. También prácticas de brujería (Suárez Guava 2009) y, en menor medida, reivindicaciones políticas asociadas a su figura (Bohórquez Castellanos 2019). En el camino del Mincho, como señalamos antes, la interacción con seres no humanos es cotidiana: se sabe quiénes son, qué hacen, qué desean y a quiénes recompensan o castigan. Sin embargo, con las brujas de la Buenavista el panorama no es claro. Más allá de saber que las brujas aparecen en forma de gualas o gallinazos, que "tumban" a las personas y que se les debe pegar para espantarlas, lo que las rodea es incierto: "hay gente que dice que dizque las brujas lo privan a uno, entonces quién sabe," comenta uno de los participantes en la cartografía social. ${ }^{8}$ Sin embargo, estas misteriosas mujeres saben bien cuál es su papel: ellas son acompañantes, guardianas y registro de memorias que claman por ser construidas.

La relación entre el conflicto armado y las brujas es estrecha. Líderes guerrilleros como Raúl Reyes, Martín Sombra y El Negro Acacio, fueron asesorados por brujas, quienes aconsejaban estrategias de acción. Guerreros de todos los bandos acuden a ellas para "rezarse" o "cruzarse"; es decir, para que sus cuerpos hechizados esquiven las balas durante el combate. Las tácticas militares se elaboran a propósito de visiones derivadas del tarot y del tabaco: 
En esto de la fe en los poderes ocultos en la guerra, Colombia, por supuesto, no es una excepción. Desde la célebre escena de las tres brujas que con sus profecías convencieron a Macbeth de que asesinara y fuera a la guerra para convertirse en rey, hasta ocultistas como Aleister Crowley, empleado por la inteligencia británica contra los alemanes en las dos guerras mundiales, la brujería ha tenido un lugar tan pintoresco como destacado en la guerra. Aunque su efectividad está por verse, aquí, en Colombia, además de guerrilleros, militares o familiares de secuestrados, no son pocos los que creen que brujas, adivinaciones y potajes pueden ayudarles a combatir el enemigo (Semana 2011).

Para el caso de la Buenavista, las brujas están lejos de alianzas militares. Al parecer, estas mujeres optan por las víctimas, los sufrientes, las personas muertas y sus familias. Lo anterior no les resta capacidad de agencia, acción o transformación. Las brujas no son personajes pasivos ni en su presencia ni en sus prácticas de embrujo. En Lengupá, como en otros territorios del país, participan activamente de la lucha por el territorio y el control social, que "también se da entre espíritus congregados" (Ospina Enciso, 2015, 116). Para esto, eligen adelantar su acción desde la Cuchilla de la Buenavista, pues en ella se materializan los límites que suelen trasgredir: la vida y la muerte, la presencia y la ausencia, la representación y la realidad; en sí, la cultura y la naturaleza.

En este sentido, Ospina señala que los espíritus corresponden a "arquetipos que condensan cualidades históricas $\mathrm{y}$ espaciales reflejadas en una entidad diferenciada pero que contiene vínculos estrechos con el mundo social que la produce" $(2016,80)$. Las brujas de la Buenavista responden a esta definición. Ellas hacen parte de la historia de violencia que ha vivido la población de la provincia de Lengupá, narran dicha historia y reclaman sobre la misma. En ese sentido, su presencia se convierte en un dispositivo de memoria, en registro o en archivo. Ellas recuerdan la tragedia al presentarse como guardianas, insisten en ella al acompañar la fila de ánimas que se lanzan al vacío y encarnan con su silencio el grito desesperado por contar lo que pasó, a quién, cómo y por qué. En términos de memorias, las brujas constituyen aquello que Arfuch (2013) define como lo inolvidadizo, expresión retomada de Nicole Loraux que se refiere a la subversión del relato desde el aparecer sin ser llamado. Una acción performática que habla de la historia en común y de la particularidad biográfica.

De esta forma, las brujas al igual que las ánimas que desfilan en la Cuchilla, reclaman el derecho a recordar siendo ellas mismas recuerdo. En el marco de una cultura caracterizada por el mestizaje espiritual (Anzaldúa, 2016, cit. En Bohorquez Castellanos 2019), las brujas hacen parte de la construcción de la memoria de la comunidad en tanto representan una narrativa de pasado reciente que permite, parafrasenado a Riaño (2006), diferenciarse de los actores armados fijando una distancia moral al reclamar su poder legítimo sobre la vida y la muerte, negociar significados de miedo, incertidumbre y dolor inscritos en lugares, y establecer un puente entre fisuras colectivas producidas por la violencia; en este caso, como acompañantes del tránsito eterno a la muerte de aquellos que no tuvieron entierros dignos.

Como en la Colonia, estas brujas se oponen a regímenes impuestos desde la violencia y la negación del otro y la otra. Usan su brujería para construir alternativas de vida allí donde la muerte parece imperar. Su presencia se traduce en crítica social y en propuesta simbólica de transformación. Evidencian que en mundos trágicos no existe dicotomía entre lo político y lo espiritual (Bohórquez Castellanos 2019) y que en el silencio de sus bocas y lo opaco de su presencia reside una reclamación profunda de reconocimiento. Las brujas evocan el conflicto armado para transgredirlo y revelarse contra él.

\section{La triple reconfiguración y el hechizo}

Las brujas, como guardianas de la Cuchilla, hacen parte de un orden simbólico en el que humanos y no humanos conviven en el mismo territorio (Bernal 2019). En tanto habitan el camino del Mincho, su presencia no sorprende, pero intriga. ¿Por qué aparecen en este lugar?; ¿Cuáles son sus pretensiones?; ¿Qué sugiere su vuelo sigiloso y su silencio? Creemos que las brujas de la Buenavista no son simple imaginería popular. Como bien lo señala Suárez (2009), la antropología contemporánea-y otras ciencias sociales - han reducido las teorías elaboradas desde la experiencia social por personas y comunidades no "expertas" a asuntos del folclor, desechando la capacidad de dichos atentes sociales de explicar el mundo. La oralidad en la provincia de Lengupá y su capacidad performativa para recrear mundos de sentido que conjugan vida, muerte, naturaleza y cultura, permite explicar por qué las brujas y su presencia resultan en mecanismos de archivo y dispositivos de memoria que activan narrativas acerca de un pasado cercano. En términos de reconstrucción de memorias, las brujas constituyen un hito a partir del cual las comunidades que habitan el camino del Mincho interpretan violencias del conflicto armado, otorgándole, a su vez, significados a lugares y territorios.

La presencia de mujeres poderosas, entendidas o sanadoras en la provincia de Lengupá se remonta a las indígenas Teguas, que eran curanderas $\mathrm{y}$, muchas veces, rebeldes. Es la figura de Genoveva "Orines," reconocida por detectar enfermedades en la orina de los enfermos y curarlos con hierbas sin requerir de procedimientos u operaciones, o de "La Cardeñosa," mujer imposible de conquistar o someter, quien cautivaba a los españoles con su belleza, solo comparable con la de las españolas (Huertas 1995). En la región, muchas mujeres han conservado saberes ancestrales derivados de los 
indígenas Teguas, como el caso de la señora Julia, conocida en su vereda como "la médica." Ella, con sus brebajes de hierbas, cura aquello que la ciencia médica no puede aliviar (Huertas 1995). En la actualidad, este tipo de prácticas son denominadas como Teguismo, en fuerte asociación con la población Tegua destacada por su medicina tradicional. ${ }^{9}$ Así pues, la imagen de mujeres sanadoras, rebeldes e, indomables, permanece en la provincia de Lengupá caracterizando el recuerdo de las ancestras. Así, no es de extrañar que las historias orales de la provincia hablen de unas mujeres que sanan el cuerpo individual y, otras, las brujas, que alivian el dolor colectivo a través de sus reclamaciones.

Nos dice Blair (2013), retomando a Ricoeur, que la memoria como narrativa tiene por efecto la reconfiguración del tiempo tomando el pasado como componente para enunciar el futuro. Las brujas hacen parte de esta narrativa al constituirse en el hilo que conecta acontecimientos, espacios, razones y protagonistas. Son ellas las encargadas de activar los recuerdos, haciéndolos emerger para que se vuelvan visibles (¿acaso materiales?) a través de sus cuerpos. Su presencia produce al menos tres reconfiguraciones importantes: la del tiempo, el cuerpo y la muerte como punto final de la vida. Con respecto al tiempo, la reconfiguración no se da en términos de futuro sino de presente y de perpetuidad. Es decir, las brujas no proyectan un futuro distinto, sino que anuncian un presente trágico perenne, imposible de transformar mientras diferentes violencias pervivan en el territorio bajo un manto de negación y silencio. Este presente irrevocable es producto de la historia de violencia que ha vivido la provincia de Lengupá desde sus tiempos más remotos, y al que las brujas hechizan congelándolo hasta tanto su clamor sea tenido en cuenta.

El cuerpo es otro escenario donde la magia de las brujas toma lugar. Su transformación en mujeres, animales o sombras representa las cualidades míticas del camino del Mincho, las cuales les permite integrarse al universo de seres no humanos que lo transitan y habitan. Como acompañantes de las ánimas que se lanzan al vacío, simulan ritos asociados a la muerte como el llanto o la despedida de quien se marcha al "más allá, " dotando, además, a la muerte de un cuerpo del que puede tomar posesión y a sus dolientes de la certeza de que sus seres queridos en efecto murieron. Es importante recordar que la Buenavista fue un lugar de desaparición donde no quedaron rastros de las muertes allí producidas, solamente la presunción de muerte, pero sin cuerpos que la constate.

Como toda bruja, las de la Buenavista tienen poder sobre la vida y la muerte y esto lo expresan haciendo de la Cuchilla un lugar liminal en el que los muertos mueren una y otra vez y los vivos poco pueden acercarse, pues, asustados ante su hechicería, prefieren darles "juete" antes que interrogarlas. Se ubica aquí aquel espacio-tiempo transicional descrito por Derrida (cit. Eljaiek-Rodríguez 2019) que es a la vez memoria y espera. Irrumpir en él no es asunto caprichoso de estas mujeres. De hecho, es la condena con la que deben lidiar por igualarse con dioses dadores de vida: ellas son guardianas del dolor de aquellos que no logran descansar reviviendo cada noche para volver a morir ${ }^{10}$. De allí su silencio: poco o nada tienen que decir ante la ruptura abrupta de órdenes sociales y simbólicos producidos por la violencia.

Es el caso de la Buenavista, las brujas que la custodian y las ánimas que se lanzan al río, Cuchilla, brujas y ánimas, forman una triada que constituye para los pobladores de Lengupá un signo de resistencia a la violencia, pues morir constantemente es rechazar la muerte manifestándose al mismo tiempo contra el olvido. Se trata también de un signo de persistencia de la memoria: "persistencia de aquello que quedó sin resolver" (Eljaiek-Rodríguez 2019, 23). Las brujas de la Buenavista son, como dice Eljaiek-Rodríguez, aterradoras y/o bondadosas, rebeldes que se niegan a hablar, a explicarse; imponen el testimonio de la muerte con su presencia.

\section{Conclusiones}

Actualmente, la academia colombiana cuenta con un acervo importante de conocimiento sobre las causas y consecuencias del conflicto armado en el país y de las formas en que las comunidades apuestan y construyen memorias. Sin embargo, faltan estudios que se concentren en territorios donde la violencia se vivió de forma menos intensa, más no por ello con menos efectos para la población. Es el caso de la provincia de Lengupá y, del departamento de Boyacá en general, territorios en los que el conflicto armado se desenvolvió diferencialmente de otras poblaciones del país y del que sabemos poco en tanto su documentación es escasa. En estos territorios, la tarea política de construcción de memoria y empoderamiento de víctimas y organizaciones apenas empieza a consolidar relatos emblemáticos que, traducidos en informes y comisiones, aporten a la verdad, la justicia y la reparación.

Pese a esto, la población no es pasiva ante los recuerdos legados por la vivencia del conflicto armado y las marcas territoriales dejadas por éste. Como lo hemos argumentado en el artículo, son diversas las estrategias utilizadas por las poblaciones para registrar recuerdos y elaborar sus memorias, significando al mismo tiempo los lugares en los que se inscriben. La experiencia de las brujas que aparecen en la Cuchilla de la Buenavista es un buen ejemplo que permite comprender que no todas las memorias del conflicto pueden elaborarse desde la narración directa del testimonio porque los contextos de enunciación no están dados, porque las poblaciones no están dispuestas a narrar o porque, como lo exponemos aquí, los registros de memoria varían de acuerdo a concepciones culturales territoriales. En el caso del Mincho, sus habitantes no humanos son quienes asumen esta responsabilidad al ser ellos quienes controlan las relaciones con la naturaleza, los 
mundos mágicos y la muerte. Tienen la posibilidad de superar el límite humano para testimoniar más allá de la vida misma.

Ante unos recuerdos que parecen perpetuos e insuperables, la imagen de las brujas resulta provocativa y estratégica, pues ellas representan rebelión. Como lo hemos señalado, mujeres sanadoras y con poderes ante la naturaleza son parte de la tradición instaurada por las indígenas Teguas en la región. A pesar de que, como cuidadoras de la Buenavista y acompañantes de las ánimas que se lanzan al río, las brujas se constituyen en portadoras de unos recuerdos circulares que no cesan, su presencia en forma de gaula y su vuelo nocturno dan cuenta de sus poderes para controvertir el pasado proponiendo futuros distintos y el rehacer del presente. Como lo hicieron en épocas remotas, estas mujeres aún filtran órdenes coloniales o de violencia armada para menoscabarlos desde sus conocimientos y hechicerías. Esta es su brujería: ellas obligan a recordar.

\section{Obras citadas}

Abierta, Verdad. 2011. "Así creció el paramilitarismo en los Llanos Orientales”. 22 de 02. Último acceso: 14 de 05 de 2020. https://verdadabierta.com/asi-crecio-el-paramilitarismo-en-los-llanos-orientales/.

Acuña, Rodriguez Olga, y Barón Javier Guerrero. 2008. “Boyacá: región y conflicto. Medellín”: La Carreta.

Arfuch, Leonor. 2013. "Memoria y autobiografía”. Buenos Aires: Fondo de Cultura Económica.

“Alza vuelo el oleoducto central.”, El Tiempo. 1995. EL TIEMPO 1.

Bernal, Diana. 2019. “El camino del Mincho. Un camino que camina.”, Maestría, Universidad Pedagógia y Tenológica de Colombia.

Blair, Elsa. 2013 “El poder del lugar y su potencial político en la legitimación de la(s) memoria(s) del conflicto político armado. "Revista cuadrenos de filosofía Latinoamericana 34, n $108:$ 65-78. https://revistas.usantotomas.edu.co/index.php/cfla/ $\underline{\operatorname{article} / \mathrm{view} / 1458}$

Bohórquez Castellanos, Marcela. 2019. «Brujas contemporáneas: entre mundos y devenires espirituales.” Nomadas 137-153. doi:DOI: 10.30578/nomadas.n50a9.

Centro Nacional de Memoria Histórica. 2013. “'Basta ya! Colombia: Memorias de guerra y dignidad». Bogotá: Imprenta Nacional.

Ehrenreich, Barbara, y Deirdre English. 2006. «Brujas, parteras y enfermeras». Olmué, Chie: METCALFE \& DAVENPORT.

«Etnografía de un recorrido». Espinel, José Ángel, entrevista de Diana Bernal. 2017. (11 de Diciembre).

Federici, Silvia. 2010. «Calibán y la bruja. Mujeres, cuerpo y acumulación originaria». Madrid: Traficante de sueños.

Garzón Martínez, María Angélica. 2015. «La subjetividad rememorante.» Revista Colombiana de Sociología 38 (2): 115-137. doi: https://doi.org/10.15446/rcs.v38n2.54902.

Guerrero Barón, Javier. 2008. «Región, ilegalidad y violencia en el caso de las guerras de las esmeraldas.» En Boyacá: Región y Conflicto, de Olga Acuña Rodríguez y Javier Guerrero Barón, 111-136. Medellín: La Carreta.

Huertas, Pedro Gustavo. 1995. «Guerreros, beldades y curanderos el enigma de los indios Teguas». Tunja: Academía Boyacense de historia.

Ingold, Tim (2008). Ways of walking. Aberdeen: Ashgate Publishing Limited

“Las Brujas de la guerra.”, Semana, Revista 2011. Último acceso: 19 de 05 de 2020. semana.com/nacion/articulo/las-brujasguerra/248172-3. 
“Los llanos, despensa petrolera colombiana.", Portafolio. 2018. Portafolio 1.

Martínez, Orlando Villanueba. 2017. "El Capitán Dumar Aljure Vida y muerte de un hombre rebelde”. Bogotá: UD.

Ospina Enciso, Andrés Felipe. 2015. "Purificando la tierra, colonizando el espíritu: conflicto armado y religiosidad en la mítica Marquetalia." Anuario de Historia Regional y de las Fronteras. 20 (2): 101-124.

.2016. "Sembrando difuntos, cosechando espíritus: Rituales de muerte y vida en los Nasa Wesx del centro de Colombia.” Boletín Antropológico 34 (91): 75-85.

Pardo, Gilma. 2016. "El Mincho. Crónicas no contadas de Lengupá”. Bogotá: Veramar.

Pérez Jiménez, Luis Orlando, y Javier Giraldo. 2018. "Hilando voces, tejiendo memorias. Tras las huellas de las violencias en Lengupá, Boyacá”. Bogotá: CINEP.

Pérez, Hector Publio. 2003. "Caminos reales de Casanare”. Yopal: Fondo Mirxto de Cultura de Casanare.

Riaño Alcalá, Pilar. 2006. “Jóvenes, memoria y violencia en Medellín”. Medellín: Universidad de Antioquia.

Eljaiek-Rodríguez, Gabriel. 2019. "Fantasmagorías bogotanas:invención y producción de fantasmas en la Candelaria." Revista de Estudios Colombianos (54): 16-27.

Rodríguez, Gustavo. 1997. "Lengupá en la Historia”. Tunja: Academia Boyacense de Historia

Różańska, Katarzyna. 2011. romanica.doc. Último acceso: 21 de 05 de 2020. https://amu.edu.pl/.

Suárez Guava, Luis Alberto. 2009. "Lluvia de flores, cosecha de huesos. guacas, brujería e intercambio con los muertos en la tragedia de Armero." Manguare (23): 371-416.

Suárez, Luis Albeto. 2009. "Lluvía de flores, cosecha de huesos. Guacas, Brujería e intercambio en la tragedia de Armero." Maguaré 371-416.

Velásquez, Tito, entrevista de Diana Bernal. 2018. "Camino del Mincho” (10 de Junio).

\section{Notas}

1. Es la división territorial de los departamentos en Colombia, no cuentan con una administración ni destinación presupuestal, su nivel de organización es de segcundaria cumpliendo una función de agrupación de los municipios según su conexión cultural, histórica, política y social.

2. Concepto usado por los pobladores de la provincia de Lengupá para referirse a las partes del camino conservadas hoy en día para el tránsito pedestre y pecuario. Es también una forma de andar que corta el camino o la carretera en tramos para llegar más rápido a un destino. Es el lugar de encuentro de los vecinos y es por dónde las personas pueden acceder a espacios públicos como la escuela, las tiendas y los puentes.

3. La violencia en la historia de Miraflores y Páez data de los años 30 del siglo XX con la llamada "Violencia," época en que liberales y conservadores se enfrentaron a muerte. La población de Miraflores y Páez en su mayoría era partidaria del liberalismo lo que convirtió a estos municipios en objetivo conservador.

4. Lo "tumban" de tumbar o hacer caer.

5. Darles “juete," o golpearlas.

6. De acuerdo con el portal Verdad Abierta, Los Masetos fue el brazo en los llanos orientales del grupo MAS (Muerte a Secues- 
tradores) creado a propósito del secuestro de Martha Nieves Ochoa, hermana de los narcotraficantes Ochoa Vásquez, líderes del Cartel de Medellín.

7. La caza de brujas data del siglo XIV extendiéndose hasta el S. XVII. Fue una práctica sistemática que inicio en Alemania y se propagó por buen parte de Europa llegando hasta Inglaterra. Financiada por los nacientes Estados y la iglesia: "Adopto diversas formas según el momento y lugar, pero sin perder en ningún momento su característica esencial de campaña de terror desencadenada por la clase dominante y dirigida contra la población campesina de sexo femenino" (Ehrenreich y English 2006, 9)

8. "Privar," o asustarse, entrar en estado de shock, desmayo provocado por un susto.

9. Teguismo, hace referencia al ejercer un ejercicio médico a partir de la curación con plantas sin tener un título profesional.

10. Comenta Eljaiek-Rodríguez (2019) a propósito de los fantasmas del barrio la Candelario en la ciudad de Bogotá (Colombia) que: "Como otros objetos de memoria o personajes culturales, los fantasmas de Bogotá y sus historias no sólo han pervivido gracias a las maldiciones que los mantienen ligados a espacios o sucesos: para seguir apareciendo (como aparición o como recreación) han necesitado de médiums que los institucionalicen y mantengan su memoria ligada al imaginario urbano" (17). 